\title{
Fingolimod and CSF neurofilament light chain levels in relapsing-remitting multiple sclerosis
}

OPEN

Jens Kuhle, MD

Giulio Disanto, MD,

$\mathrm{PhD}$

Johannes Lorscheider, MD

Tracy Stites, MD

Yu Chen, MS

Frank Dahlke, MD

Gordon Francis, MD

Anupama Shrinivasan,

$\mathrm{PhD}$

Ernst-Wilhelm Radue, MD

Gavin Giovannoni, MD, $\mathrm{PhD}$

Ludwig Kappos, MD

Correspondence to

Dr. Kuhle:

jens.kuhle@usb.ch

\section{ABSTRACT}

Objective: We assessed CSF levels of the light chain subunit of neurofilaments (NfL) at baseline and after fingolimod therapy or placebo in patients with relapsing-remitting multiple sclerosis (RRMS). Changes in NfL levels were also correlated with relapse and MRI outcomes.

Methods: CSF samples were available, at baseline and 12 months after treatment initiation, from a subset of 36 patients with RRMS (fingolimod $0.5 \mathrm{mg}: \mathrm{n}=9$; fingolimod $1.25 \mathrm{mg}: \mathrm{n}=15$; placebo: $n=12$ ) participating in the 2-year, phase 3 Fingolimod (FTY720) Research Evaluating Effects of Daily Oral Therapy in Multiple Sclerosis (FREEDOMS) study. NfL levels were determined in a blinded fashion using a commercial ELISA kit.

Results: Median NfL levels did not differ between treatment groups at baseline $(0.5 \mathrm{mg}: 644 \mathrm{pg} /$ $\mathrm{mL} ; 1.25 \mathrm{mg}: 659 \mathrm{pg} / \mathrm{mL}$; pooled 0.5/1.25 mg: $652 \mathrm{pg} / \mathrm{mL}$, placebo: $886 \mathrm{pg} / \mathrm{mL} ; \mathrm{p}$ value [fingolimod vs placebo] $=0.619,0.495$, and 0.481 , respectively). Following 12 months of treatment, median changes from baseline in NfL levels were lower than zero in the fingolimod groups $(0.5 \mathrm{mg}$ : $-346 \mathrm{pg} / \mathrm{mL}, \mathrm{p}=0.039 ; 1.25 \mathrm{mg}:-313 \mathrm{pg} / \mathrm{mL}, \mathrm{p}=0.035$ ) and pooled $0.5 / 1.25 \mathrm{mg}$ fingolimod group $(-326 \mathrm{pg} / \mathrm{mL}, 83.3 \%$ with reduction, $\mathrm{p}=0.002)$ but not in the placebo group $(-214 \mathrm{pg} /$ $\mathrm{mL}, 66.7 \%$ with reduction, $\mathrm{p}=0.388$ ). Reductions in $\mathrm{NfL}$ levels at month 12 correlated with an improvement in relapse and MRI outcomes.

Conclusions: Our results suggest a beneficial effect of fingolimod on this marker of axonal injury and support the utility of $\mathrm{NfL}$ as a quantitative biomarker in multiple sclerosis. Neurology ${ }^{\circledR}$ 2015;84:1639-1643

\section{GLOSSARY}

ANCOVA $=$ analysis of covariance; EDSS $=$ Expanded Disability Status Scale; FREEDOMS = Fingolimod (FTY720) Research Evaluating Effects of Daily Oral Therapy in Multiple Sclerosis; $\mathbf{M S}=$ multiple sclerosis; $\mathbf{N f}=$ neurofilaments; $\mathbf{N f H}=$ heavy chain subunit of neurofilaments; $\mathbf{N f L}=$ light chain subunit of neurofilaments; RRMS = relapsing-remitting multiple sclerosis.

Neurofilaments (Nf) are neuronal structural proteins composed of 4 subunits: the triplet of Nflight (NfL), Nf-medium, and Nf-heavy (NfH) chains, and $\alpha$-internexin in the CNS, or peripherin in the peripheral nervous system. Nf subunits have emerged as promising biomarkers of axonal injury in multiple neurologic disorders.

Progressive neurodegeneration occurring secondary to inflammation and primary neurodegeneration is a hallmark of multiple sclerosis (MS) and a key contributor to disability progression. ${ }^{2}$ There is a need for soluble, quantitative biomarkers that could provide an early indication of neurodegeneration and response to therapies.

In MS, increased CSF levels of NfL and NfH have been reported in all stages of the disease. ${ }^{3}$ A recent, uncontrolled study reported significant reductions in CSF NfL and NfH levels in response to natalizumab therapy. Changes in NfL levels were more pronounced than $\mathrm{NfH} .{ }^{4,5}$

\footnotetext{
From the Neuroimmunology Unit (J.K., G.D., G.G.), Blizard Institute, Barts and the London School of Medicine and Dentistry, London, UK; Neurology, Departments of Medicine, Clinical Research and Biomedicine (J.K., J.L., L.K.), and the Medical Image Analysis Center (MIAC) (E.-W.R.), University Hospital, Basel, Switzerland; Novartis Pharmaceuticals Corporation (T.S., Y.C., G.F.), East Hanover, NJ; Novartis Pharma AG (F.D.), Basel, Switzerland; and Novartis Healthcare Pvt Ltd (A.S.), Hyderabad, India.

Go to Neurology.org for full disclosures. Funding information and disclosures deemed relevant by the authors, if any, are provided at the end of the article. The Article Processing Charge was paid by institutional funding (University Hospital Basel).

This is an open access article distributed under the terms of the Creative Commons Attribution-Noncommercial No Derivative 3.0 License, which permits downloading and sharing the work provided it is properly cited. The work cannot be changed in any way or used commercially.
} 
Fingolimod $0.5 \mathrm{mg}$ once-daily (Gilenya, Novartis Pharma AG, Basel, Switzerland), a sphingosine-1-phosphate receptor modulator, is the first oral therapy approved for relapsing-remitting MS (RRMS). Preclinical findings ${ }^{6}$ and consistent effects on brain atrophy observed in 3 phase III MS clinical trials ${ }^{7-9}$ suggest fingolimod has potential neuroprotective properties.

Here we report the effects of fingolimod on CSF NfL levels in RRMS compared with placebo. We also explored correlations between CSF NfL with clinical and imaging outcomes in placebo and fingolimod-treated patients, separately and combined.

METHODS This was a post hoc investigation of NfL in CSF samples collected at baseline and month 12 in a subgroup of patients with RRMS participating in the 2-year, placebo-controlled, phase 3 Fingolimod (FTY720) Research Evaluating Effects of Daily Oral Therapy in Multiple Sclerosis (FREEDOMS) study (ClinicalTrials.gov number, NCT00289978) that evaluated fingolimod at the doses of 0.5 mg and $1.25 \mathrm{mg}$ once daily. ${ }^{7}$ Provision of CSF samples was an optional component of the FREEDOMS study protocol. Definitions and methodologies of clinical and MRI assessments have been described previously. ${ }^{7}$

CSF samples were available from 36 patients $(0.5 \mathrm{mg}, \mathrm{n}=9$; $1.25 \mathrm{mg}, \mathrm{n}=15$; placebo, $\mathrm{n}=12$ ). CSF NfL levels were measured using the Uman Diagnostics NF-light ELISA kit (Umeå, Sweden). The assay was conducted blinded to the clinical data and treatment allocation. ${ }^{3-5}$ Interassay and intra-assay variability (coefficients of variation) in 3 longitudinal control samples were below $15 \%$.

Standard protocol approvals, registrations, and patient consents. Protocol approvals and registration details have been described previously.7 The study was approved by the local institutional review boards. All patients provided written informed consent.

Statistical analysis. Variables are described as medians (interquartile range) or numbers and percentages. The Mann-Whitney test was used for between-group comparisons $(0.5 \mathrm{mg}, 1.25 \mathrm{mg}$, and pooled fingolimod-treated [ $0.5 \mathrm{mg}$ and $1.25 \mathrm{mg}$ ] vs placebo). In addition, we performed an analysis of covariance (ANCOVA) on rank transformed data (rank analysis of covariance) adjusted for treatment and baseline NfL levels as a sensitivity analysis for between-group comparison at month 12 . The sign test was used to evaluate longitudinal comparisons, i.e., to test whether the median for change from baseline is different from zero. Correlations were analyzed using the Spearman correlation methodology. Correlation

\section{Table Baseline and month 12 results}

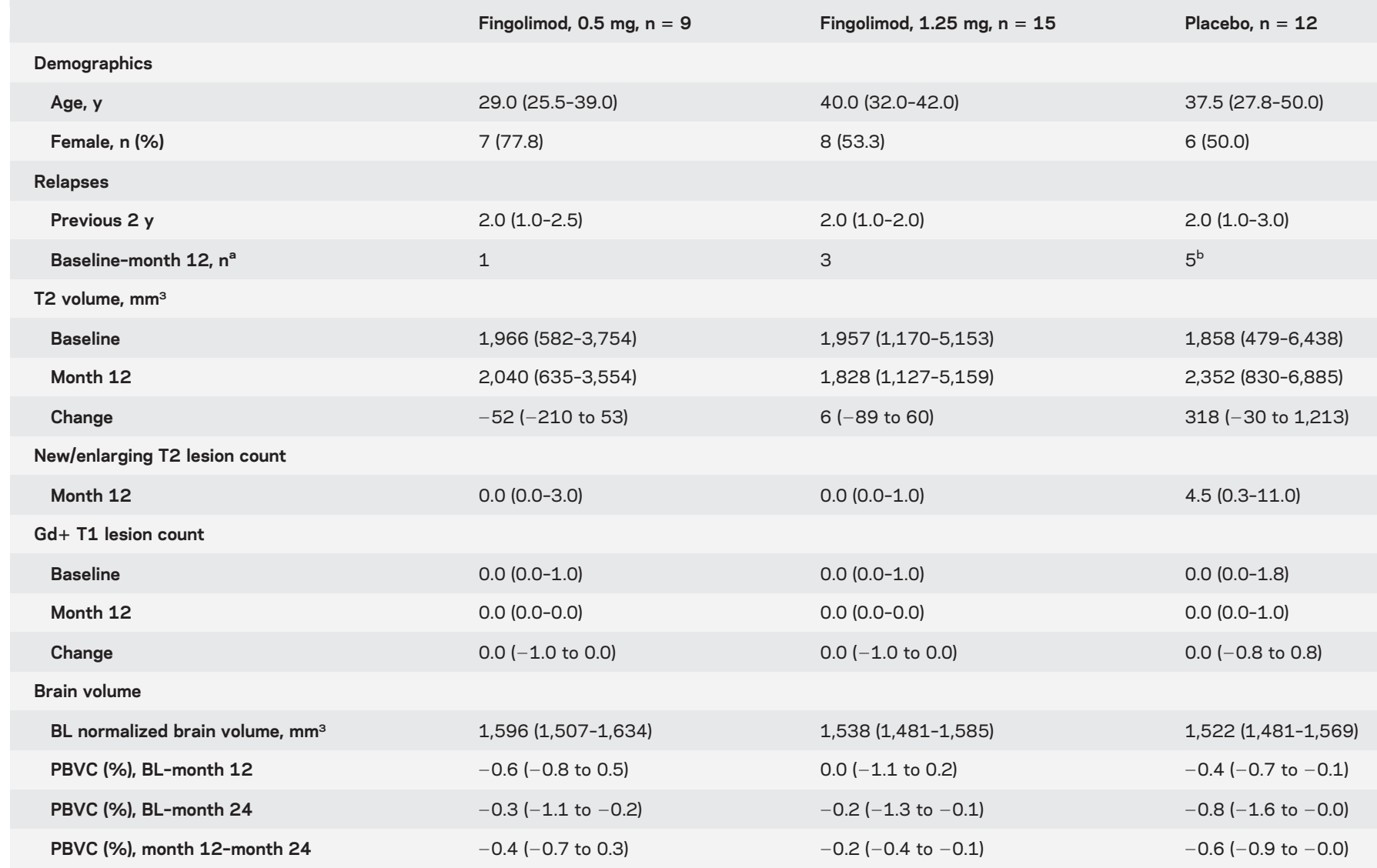

Abbreviations: $\mathrm{Gd}+=$ gadolinium-enhancing; PBVC = percentage brain volume change.

Values are median (interquartile range) unless indicated otherwise.

${ }^{a}$ Confirmed relapses.

${ }^{\mathrm{b}}$ Two patients experienced 2 relapses and 1 patient experienced 1 relapse. 
analyses on endpoints at the same time points were based on data pooled from the 3 treatment arms. Correlation analyses on endpoints from different time points, e.g., at baseline vs at month 12 , were based on data pooled from both doses of fingolimod ( 0.5 $\mathrm{mg}$ and $1.25 \mathrm{mg}$ ) and data from the placebo arm separately in order to avoid the confounding effect from the treatment. A 2 -sided $p$ value $<0.05$ was considered significant. All analyses were conducted using SPSS (version 20, Chicago, IL) and GraphPad Prism 6.04 (GraphPad Software, San Diego, CA).

One patient discontinued from the fingolimod $1.25 \mathrm{mg}$ group due to an adverse event (increased liver enzymes) after 6.4 months on treatment (patient Y).

RESULTS Baseline and study characteristics of the 36 patients evaluated in this study are presented in the table. The median time since onset of the last

Figure 1 Neurofilament light chain levels at baseline and after 12 months, cross-sectional analysis

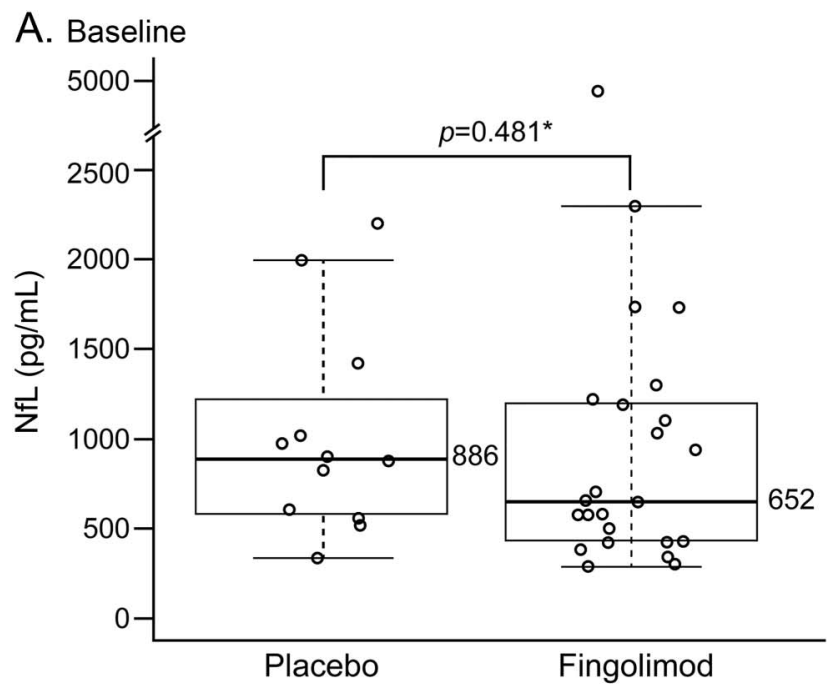

B. 12 months

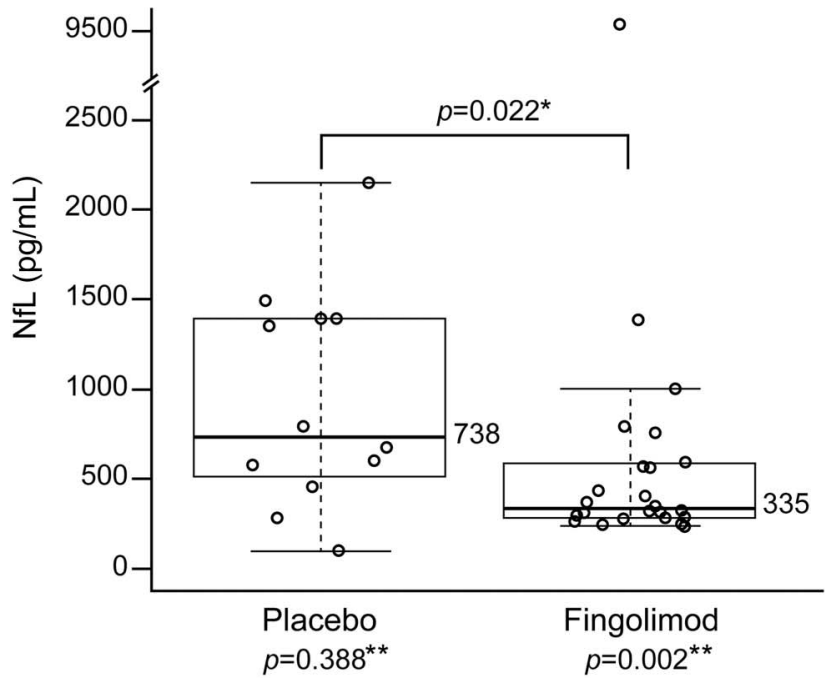

Neurofilament light chain ( $\mathrm{NfL}$ ) levels at baseline (A); pooled fingolimod 0.5/1.25 mg: $652 \mathrm{pg} /$ $\mathrm{mL}$; placebo: $886 \mathrm{pg} / \mathrm{mL}, \mathrm{p}=0.481$. At 12 months (B), NfL levels pooled fingolimod group: $335 \mathrm{pg} / \mathrm{mL}$; placebo: $738 \mathrm{pg} / \mathrm{mL}, p=0.022$. *Mann-Whitney test. **Sign test: baseline vs month 12. Dots represent individual samples. Box and whiskers plotted according to the Tukey method. relapse to baseline was 159 days (122-277). During the study, 3 patients on placebo experienced a total of 5 relapses. Two patients in the fingolimod groups reported one confirmed relapse each, and 1 patient in the fingolimod $1.25 \mathrm{mg}$ group experienced 2 confirmed relapses. One patient in the placebo group had an acute (defined as onset within 30 days before CSF sampling) relapse with onset 13 days prior to CSF sampling at month 12 . In line with the phase 3 study results, ${ }^{7}$ fingolimod treatment led to reductions in relapses and MRI new lesion formation; however, the small sample size allowed for only qualitative comparisons.

Effect of fingolimod treatment on NfL levels. NfL levels at baseline were comparable across the treatment groups $(0.5 \mathrm{mg}$ : $644 \mathrm{pg} / \mathrm{mL} ; 1.25 \mathrm{mg}: 659 \mathrm{pg} / \mathrm{mL}$; pooled fingolimod 0.5/1.25 mg: $652 \mathrm{pg} / \mathrm{mL}$; placebo: $886 \mathrm{pg} / \mathrm{mL} ; p$ value [fingolimod vs placebo] $=0.619$, 0.495 , and 0.481 , respectively) (figure $1 \mathrm{~A})$. By month 12, NfL levels decreased as compared to baseline in the fingolimod-treated groups $(0.5 \mathrm{mg}$ : median change from baseline: $-346 \mathrm{pg} / \mathrm{mL}[88.9 \%$ with reduction], $p=0.039$, figure $2 \mathrm{~A} ; 1.25 \mathrm{mg}$ : $-313 \mathrm{pg} / \mathrm{mL}$ [80.0\% with reduction], $p=0.035$, figure $2 \mathrm{~B}$; and pooled fingolimod $0.5 / 1.25 \mathrm{mg}:-326$ $\mathrm{pg} / \mathrm{mL}$ [83.3\% with reduction], $p=0.002$ ), while the median reduction in the placebo group between baseline and month 12 was not significantly different from zero $(-214 \mathrm{pg} / \mathrm{mL}$ [66.7\% with reduction], $p=0.388$, figure 2C). At month 12, NfL levels were lower in the pooled fingolimod group than placebo $(p=0.022$, figure $1 \mathrm{~B} ; p=0.028$, for rank ANCOVA including baseline NfL level adjustment as a sensitivity analysis).

Evaluation of NfL outliers. Four patients, 1 each in the placebo and fingolimod $0.5 \mathrm{mg}$ groups and 2 in the fingolimod $1.25 \mathrm{mg}$ group, showed extreme changes in NfL levels at month 12 compared with baseline (figure 2, A-C). The overall results were not affected by exclusion of these outlier patients from the analysis (data not shown).

Patients W (figure 2A) and X (figure 2B) in the fingolimod groups showed a marked reduction in NfL levels at month 12 vs baseline. These were paralleled by clinical and paraclinical improvements over the 12-month observation period. Patient Y (figure 2B) experienced a marked increase in NfL levels, paralleled by 2 relapses, an increase in Expanded Disability Status Scale (EDSS) score, and T2 lesion volume. This patient subsequently discontinued from the study drug after 6.4 months due to an adverse event. Patient $Z$ (placebo; figure 2C) experienced an increase in NfL levels at month 12 compared with baseline and a corresponding increase in EDSS. 
Figure 2 Patient profiles of changes in neurofilament light chain levels from baseline to month 12

A. Fingolimod $0.5 \mathrm{mg}(\mathrm{n}=9)$

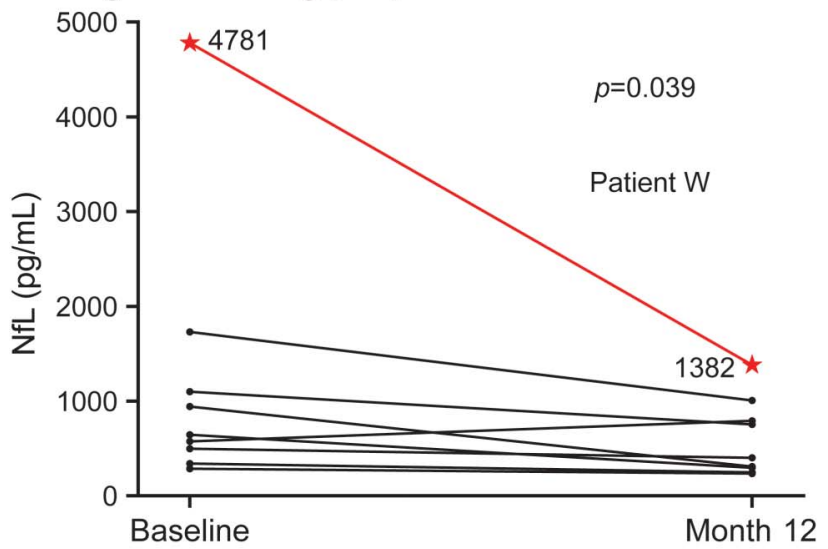

B. Fingolimod $1.25 \mathrm{mg}(\mathrm{n}=15)$

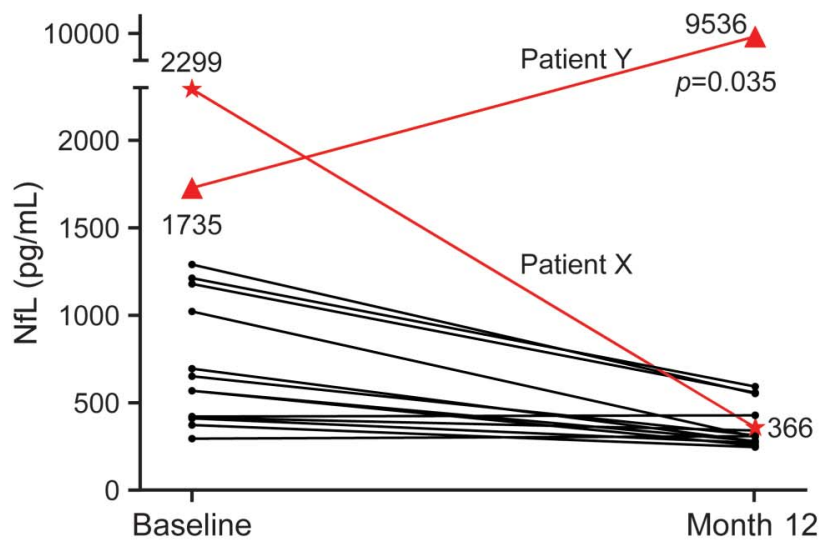

C. Placebo $(n=12)$

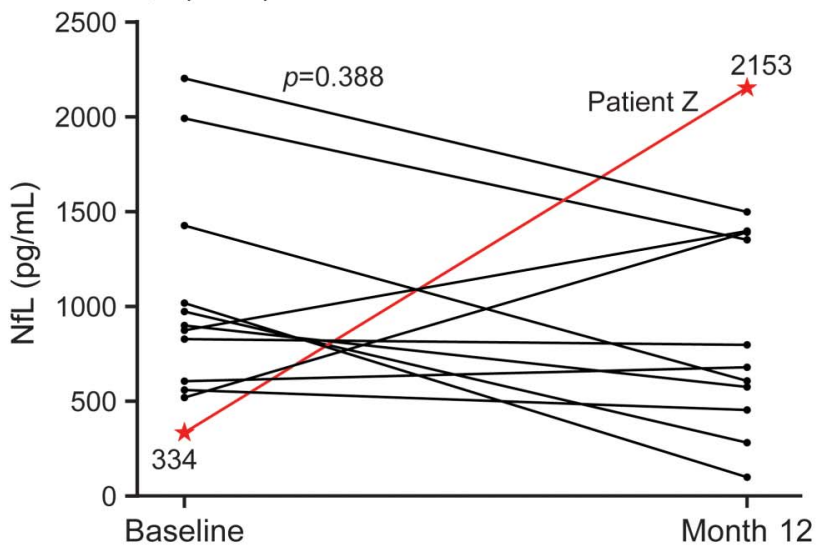

Median change from baseline in neurofilament light chain (NfL) levels at month 12: (A) fingolimod $0.5 \mathrm{mg}$ : $-346 \mathrm{pg} / \mathrm{mL}, \mathrm{p}=0.039$; (B) fingolimod $1.25 \mathrm{mg}:-313 \mathrm{pg} / \mathrm{mL}, \mathrm{p}=0.035$; (C) placebo $-214 \mathrm{pg} / \mathrm{mL}, p=0.388$. Patient W: Expanded Disability Status Scale score (EDSS) decreased from 2 to 1.5; reduction in gadolinium-enhancing $(\mathrm{Gd}+)$ lesions from 5 to 0 ; decrease in T2 lesion volume $\left(12,309 \mathrm{~mm}^{3}-11,828 \mathrm{~mm}^{3}\right)$ and no relapses. Patient X: stable EDSS score of $1.5 ; \mathrm{no} \mathrm{Gd}+$ lesions (both time points); stable T2 lesion volume $\left(5,153 \mathrm{~mm}^{3}-5,159 \mathrm{~mm}^{3}\right)$ and no relapses. Patient Y: EDSS from 1.5 to 4.5; reduction in $\mathrm{Gd}+$ lesions from 1 to 0 ; increase in T2 lesion volume (6,512 $\left.\mathrm{mm}^{3}-23,794 \mathrm{~mm}^{3}\right)$; 2 relapses. Patient Z: increase in EDSS (3-4.5); increase in $\mathrm{Gd}+$ lesions from 1 to 7 ; increase in T2 lesion volume $\left(5,888 \mathrm{~mm}^{3}-6,569 \mathrm{~mm}^{3}\right) ; 2$ relapses.

Correlation analysis. Baseline CSF NfL levels did not correlate with age $(r=-0.10, p=0.57)$ or sex, although trending to higher values in men (women:
$576 \mathrm{pg} / \mathrm{mL}$ [426-920], men: $1,028 \mathrm{pg} / \mathrm{mL}$ [6591,297], $p=0.077$ ).

Month $12 \mathrm{NfL}$ levels were higher in patients who experienced relapses during the study $(1,448 \mathrm{pg} / \mathrm{mL}$ [494-3,999]) vs those who did not $(384 \mathrm{pg} / \mathrm{mL}$ [285698], $p=0.014$ ). In patients receiving placebo, month $12 \mathrm{NfL}$ correlated with month 12 EDSS $(r=0.65, p=$ $0.021, \mathrm{n}=12)$ as well as EDSS change from baseline to month $12(r=0.58, p=0.047, \mathrm{n}=12)$. Similar correlations did not reach statistical significance in the entire cohort or for patients treated with fingolimod.

Across all groups, patients with higher baseline NfL levels had a larger T2 lesion volume at baseline $(r=0.40, p=0.015)$. Month $12 \mathrm{NfL}$ levels and new/enlarging T2 lesions count $(r=0.57, p<$ $0.001)$ were also correlated. Patients with higher NfL levels had lower normalized brain volume $(r=$ $-0.41, p=0.014$ ) across all groups at baseline. Correlations of percentage brain volume change from baseline to months 12 and 24 and from months 12 to 24 with baseline NfL levels in both fingolimod $\left(r_{\mathrm{M} 12}=-0.21, p=0.326 ; r_{\mathrm{M} 24}=-0.39, p=\right.$ $\left.0.058 ; r_{\mathrm{M} 12-\mathrm{M} 24}=-0.53, p=0.008, \mathrm{n}=24\right)$ and placebo $\left(r_{\mathrm{M} 12}=-0.17, p=0.602 ; r_{\mathrm{M} 24}=\right.$ $-0.47, p=0.124 ; r_{\mathrm{M} 12-\mathrm{M} 24}=-0.45, p=0.14$, $\mathrm{n}=12$ ) groups, except in one instance, did not reach statistical significance.

DISCUSSION Our data show that CSF NfL levels decreased substantially in fingolimod-treated patients but not in patients on placebo. The treatment effect on NfL levels was associated with improved clinical and MRI outcomes. At the individual patient level, extreme changes in CSF NfL levels, irrespective of treatment, were reflected in the clinical and paraclinical findings.

We did observe a weak reduction of NfL levels in the placebo group, which could either represent a regression to the mean effect, given that the study inclusion criteria selected for patients with active disease before baseline, or possibly just a random variation in NfL levels. Regardless of its cause, this reduction was not statistically significant, and NfL levels were considerably lower in fingolimod-treated patients vs placebo at month 12 , even in the less sensitive across-group comparison. Also, baseline NfL levels were slightly higher in the placebo group compared to both fingolimod groups. However, to the extent that this difference could have potentially influenced the results, the tendency probably would have been expected to decrease the evidence of a treatment effect (i.e., because it is more difficult to see improvement in a group starting with lower baseline values). In addition, a rank ANCOVA analysis that adjusted for baseline yielded similar evidence of an effect $(p=0.028)$. 
Consistent with our study results, a recent uncontrolled study in patients with RRMS with high disease activity suggested an association of natalizumab treatment with a decrease in CSF NfL levels and corresponding improvements in clinical, MRI, and other laboratory measures. ${ }^{4}$ Our study confirms in a placebo-controlled study setting that immunomodulatory therapies can impact on CSF NfL levels. Taken together, the role of CSF NfL quantification as a measure of neuroaxonal damage is corroborated by the observed association with MRI markers of disease activity, and the trend for an association with the development of brain volume loss, adding to the body of previous evidence. Pronounced changes in NfL levels with fingolimod therapy as opposed to placebo further suggest the usefulness of NfL levels as a putative biomarker of axonal damage in MS clinical trials. The reduction of NfL levels by treatment could either be related to the well-known immunomodulatory effects of fingolimod or to potential direct effects of the drug on CNS cells. ${ }^{6}$

Limitations of this study include the post hoc nature of the analyses and the small sample size. The latter is driven by the limited number of paired CSF samples available from the FREEDOMS trial. It is unclear if the results found in this sample would be mirrored by the full study population. The findings of this study are of interest and serve to generate hypotheses about the utility of NfL as a biomarker of disease activity, tissue damage, and treatment effect. Our results support the need for future larger scale studies including CSF sampling and investigating easier accessible compartments like peripheral blood to further examine the utility of NfL levels as a potential biomarker in MS. ${ }^{10}$

\section{AUTHOR CONTRIBUTIONS}

All authors drafted/revised the manuscript for intellectual content. J. Kuhle, G. Francis, G. Giovannoni, and L. Kappos conceptualized and designed the study. J. Kuhle and Y. Chen conducted statistical analysis of the data from the study. Authors who carried out the biostatistical analysis: J. Kuhle, Neuroimmunology Unit, Blizard Institute Barts, and the London School of Medicine and Dentistry, London, UK, and Neurology, University Hospital Basel, Switzerland; and Y. Chen, Novartis Pharmaceuticals Corporation, East Hanover, NJ.

\section{ACKNOWLEDGMENT}

The authors thank Hedwig Wariwoda and Rocco Adiutori for technical support; and Rishard Salie, Novartis Pharma AG, for coordinating author review and feedback on the draft manuscript, and organizing author discussions.

\section{STUDY FUNDING}

Funded by the University Hospital Basel and Novartis Pharma AG, Basel.

\section{DISCLOSURE}

J. Kuhle is supported by an ECTRIMS Research Fellowship Programme and by the Forschungsfonds of the University of Basel, Switzerland; has received research support from the Swiss MS Society, Swiss ALS Society, Protagen AG, Roche, and Novartis; and served on scientific advisory boards for Genzyme/Sanofi-Aventis, Merck Serono, and Novartis Pharma. G. Disanto and J. Lorscheider report no disclosures relevant to the manuscript. T. Stites is an employee of Novartis Pharmaceuticals Corporation, East Hanover, NJ. Y. Chen is an employee of Novartis Pharmaceuticals Corporation, East Hanover, NJ. F. Dahlke is an employee of Novartis Pharma AG, Basel, Switzerland. G. Francis is an employee of Novartis Pharmaceuticals Corporation, East Hanover, NJ. A. Shrinivasan is an employee of Novartis Healthcare Pvt Ltd, Hyderabad, India. E. Radue has received honoraria for serving as speaker at scientific meetings and consultant for Novartis, Biogen Idec, Merck Serono, and Bayer Schering. He has received financial support for research activities from Actelion, Basilea Pharmaceutica Ltd, Biogen Idec, Merck Serono, and Novartis. G. Giovannoni has received research grant support from Bayer-Schering Healthcare, Biogen-Idec, GW Pharma, Merck Serono, Merz, Novartis, Teva, and Sanofi-Aventis. He has received personal compensation for participating on Advisory Boards in relation to clinical trial design, trial steering committees, and data and safety monitoring committees from Bayer-Schering Healthcare, BiogenIdec, Eisai, Elan, Fiveprime, Genzyme, Genentech, GSK, GW Pharma, Ironwood, Merck-Serono, Novartis, Pfizer, Roche, Sanofi-Aventis, Synthon BV, Teva, UCB Pharma, and Vertex Pharmaceuticals. L. Kappos' institution, University Hospital Basel, received research support from Actelion, Advancell, Allozyne, BaroFold, Bayer Health Care Pharmaceuticals, Bayer Schering Pharma, Bayhill, Biogen Idec, BioMarin, CSL Behring, Elan, Genmab, Genmark, GeNeuro SA, GlaxoSmithKline, Lilly, Merck Serono, MediciNova, Novartis, Novo Nordisk, Peptimmune, sanofi-aventis, Santhera, Roche, Teva, UCB, Wyeth, the Swiss MS Society, the Swiss National Research Foundation, the European Union, and the Gianni Rubatto, Novartis, and Roche Research Foundations. Go to Neurology.org for full disclosures.

Received May 26, 2014. Accepted in final form December 15, 2014.

\section{REFERENCES}

1. Petzold A. Neurofilament phosphoforms: surrogate markers for axonal injury, degeneration and loss. J Neurol Sci 2005; 233:183-198.

2. Confavreux C, Vukusic S. Natural history of multiple sclerosis: a unifying concept. Brain 2006;129:606-616.

3. Kuhle J, Plattner K, Bestwick JP, et al. A comparative study of CSF neurofilament light and heavy chain protein in MS. Mult Scler 2013;19:1597-1603.

4. Gunnarsson M, Malmestrom C, Axelsson M, et al. Axonal damage in relapsing multiple sclerosis is markedly reduced by natalizumab. Ann Neurol 2011;69:83-89.

5. Kuhle J, Malmestrom C, Axelsson M, et al. Neurofilament light and heavy subunits compared as therapeutic biomarkers in multiple sclerosis. Acta Neurol Scand 2013;128:e33-e36.

6. Miron VE, Ludwin SK, Darlington PJ, et al. Fingolimod (FTY720) enhances remyelination following demyelination of organotypic cerebellar slices. Am J Pathol 2010; 176:2682-2694.

7. Kappos L, Radue EW, O'Connor P, et al. A placebocontrolled trial of oral fingolimod in relapsing multiple sclerosis. N Engl J Med 2010;362:387-401.

8. Cohen JA, Barkhof F, Comi G, et al. Oral fingolimod or intramuscular interferon for relapsing multiple sclerosis. N Engl J Med 2010;362:402-415.

9. Calabresi PA, Radue EW, Goodin D, et al. Safety and efficacy of fingolimod in patients with relapsing-remitting multiple sclerosis (FREEDOMS II): a double-blind, randomised, placebo-controlled, phase 3 trial. Lancet Neurol 2014;13:545-556.

10. Gaiottino J, Norgren N, Dobson R, et al. Increased neurofilament light chain blood levels in neurodegenerative neurological diseases. PLoS One 2013;8:e75091. 


\section{Neurology}

\section{Fingolimod and CSF neurofilament light chain levels in relapsing-remitting multiple sclerosis}

Jens Kuhle, Giulio Disanto, Johannes Lorscheider, et al.

Neurology 2015;84;1639-1643 Published Online before print March 25, 2015

DOI 10.1212/WNL.0000000000001491

\section{This information is current as of March 25, 2015}

\section{Updated Information \& \\ Services}

Supplementary Material

\section{References}

Citations

Subspecialty Collections

Permissions \& Licensing

Reprints including high resolution figures, can be found at: http://n.neurology.org/content/84/16/1639.full

Supplementary material can be found at: http://n.neurology.org/content/suppl/2015/03/25/WNL.0000000000001 491.DC1

This article cites 10 articles, 0 of which you can access for free at: http://n.neurology.org/content/84/16/1639.full\#ref-list-1

This article has been cited by 8 HighWire-hosted articles: http://n.neurology.org/content/84/16/1639.full\#\#otherarticles

This article, along with others on similar topics, appears in the following collection(s):

All Clinical trials

http://n.neurology.org/cgi/collection/all_clinical_trials

Cerebrospinal Fluid

http://n.neurology.org/cgi/collection/cerebrospinal_fluid Multiple sclerosis

http://n.neurology.org/cgi/collection/multiple_sclerosis

Information about reproducing this article in parts (figures,tables) or in its entirety can be found online at:

http://www.neurology.org/about/about_the_journal\#permissions

Information about ordering reprints can be found online:

http://n.neurology.org/subscribers/advertise

Neurology ${ }^{\circledR}$ is the official journal of the American Academy of Neurology. Published continuously since 1951, it is now a weekly with 48 issues per year. Copyright @ 2015 American Academy of Neurology. All rights reserved. Print ISSN: 0028-3878. Online ISSN: 1526-632X.

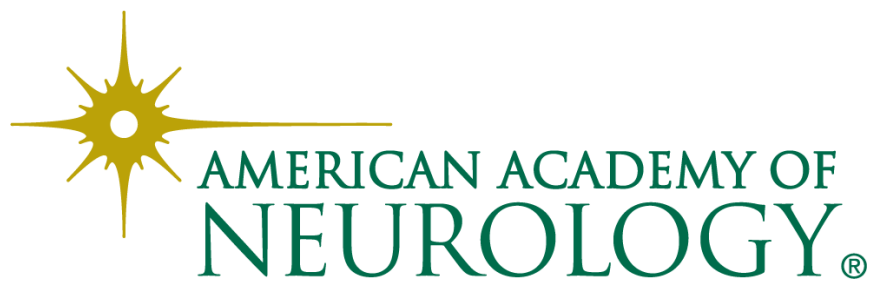

